\title{
Schedule Management in Underground Municipal Pipe Network Construction Based on BIM Technology
}

\author{
Xiaohan Han, Jiayuan Wang, Miao Qun*, Xiaotong Cui, Linlin Liu \\ School of Environment and Municipal Engineering, Qingdao University of Technology, Qingdao, \\ Shandong, 266033, China \\ lgdma@163.com
}

\begin{abstract}
Keywords: Building information modeling(BIM), Schedule management, Underground municipal pipe network.

Abstract. According to the characteristics of the municipal pipe network, analyze the current status of the construction progress of the municipal pipe network and summarize the reasons for the low efficiency of the municipal. This paper puts forward the construction progress management method of the underground municipal pipe network, and takes the underground pipe network project of Qingdao Juxian Bridge Road section as an example to effectively improve the efficiency of the construction schedule management.
\end{abstract}

\section{Introduction}

BIM is an abbreviation of Building Information Modeling, based on 3D digital technology, BIM integrates the engineering data model of various related information of construction project. It is a detailed expression of the relevant information of the project. BIM technology is the product of building informatization. The industry generally believes that the application of BIM technology is a trend in the future development, the trend of BIM technology application has been unstoppable.

Schedule management is an important part in construction engineering project management, which is easily affected by some objective and subjective factors, such as construction complexity, social environment uncertainty, unreasonable schedule plan etc. Therefore, in each item project, there does exist lag duration between actual construction period and planned construction period. It is difficult to control the project schedule in common project schedule management practice. However, the emergence of BIM technology bring about new ideas in construction schedule management about underground municipal pipe network.

\section{Traditional construction schedule management of underground municipal pipe network}

Underground municipal pipe network is an extremely complex and tremendous system. So far, urban underground pipe network in China has been divided into eight different kinds systems, such as water supply, sewage, heat supply, power supply, communication, gas .etc, which covered more than 20 species of pipeline. All kinds of pipeline system have their own design, construction and management pattern. As the municipal pipe network expanding and changing, the pipeline system become more complex. Due to its the huge quantity, wide varieties, and complex position, underground pipelines are difficult to manage.

Gantt Chart, Network Planning Technology, Critical Chain Project Management, Project, P6 were applied to the traditional underground pipe network construction schedule management to improve project management level. However, due to the unreasonable organization structure and the process as well as the limitation of the oral or written expression, there are many problems still to be solved in the traditional schedule management which only depend on the gerentocratic experience and their subjective judgment, such as slow reaction, irregular adjustment, lack of effective communication between the project unit, block of information. Traditional project schedule management techniques can improve the efficiency of the project schedule management to a certain degree, but it has great limitation. 


\section{Underground municipal pipeline construction schedule management based on BIM}

Construction schedule simulation technology under BIM platform is to add time dimension to the three-dimensional building information model space, so as to form 4D model and to perform a construction process simulation by using computer. The establishment of BIM-4D is the key progress promoting BIM applied to schedule management. BIM model contains the basic geometric information, material properties, physical properties, equipment production information, progress information and other types of information. The 4D-model of underground municipal pipe network is built on the 3D-model and connect the construction schedule.

BIM technology provides an accurate, efficient and non-destructive progress information transmission channel for the progress team, which increases the communication and interaction between the parties involved in the project and improves the efficiency of construction schedule management by querying real-time information based on the construction information model. Through intuitive and dynamic visual construction schedule simulation and progress simulation of key aspects, you can show a variety of practical operation of construction plans and process plans, and make best choice of the most appropriate program. Schedule delays can be reduced or even avoided by planning construction progress reasonably, control construction progress precisely, configuring construction resources dynamicly, decorating construction site rationally, as well as enough resource supply and working space. BIM can enhance team collaboration and greatly shorten the construction period. Therefore, the efficiency of construction schedule management can be greatly improved.

\section{The establishment of BIM-4D Model}

The underground pipe network project of Juxian Bridge Road involves the water supply, drainage, gas, electricity, telecommunications ect. This paper mainly uses BIM technology to construct the urban road and underground pipe network model. This project uses Revit software to create five systems of road, water supply, sewage, rainwater and reclaimed water, and finish the 3D model of the underground pipe network cooperatively.

According to WBS (Work Breakdown Structure), the whole project is divided into individual projects and sub-projects. By allocating the overall scheduling plan to each node and adding the nodes duration and task logic relationship, then the project schedule will be initially completed. According to the requirements of a whole construction period and resource allocation, fully considered the basic situation of construction flow section division, construction scheme and construction technology. The Project management software is used in this pipeline network project, makes a uniform establishiment for an overall engineering project and the pipeline construction sequence and scheduling based on section, layer and combination in single engineering projects, and develops a corresponding Gantt chart.

In order to ensure the one-to-one correspondence between the model components and the schedule, when the BIM-3D model is integrated by Navisworks software, the components in the model are subdivided in descending order according to the group and type, at the same time, use the function "Timeliner" to connect the Project schedule file in "mpp" format. Associated each task in schedule with its corresponding model components, so as to achieve the perfect connection between BIM model, Gantt chart and schedule task, thus to finish the construction of underground pipe network BIM-4D model, as is shown in Figure 1.

\section{The application of BIM in underground municipal pipeline schedule management}

Based on BIM 4D construction simulation, on the one hand, it can realize the visualization management of underground pipe network's whole construction process, and according to the schedule to optimize the allocation of human, material, machine and other resources. On the other hand, it can analyze the key points and difficult points in construction process, and formulate a local pipe network optimization program, to better control the progress of the project. The project according to the overall schedule and water construction principles, stratified sub-regional construction, as is shown in Figure 2. Before the underground municipal pipe network construction, 
reversible construction simulation based on BIM technology can check the potential design loopholes which do not against the standards, and directly expose other irrational construction problems such as security measures and site layout, to make up for practical difficulties in construction stage. To find problems as soon as possible in 4D model, adjust and optimize the schedule and construction organization, can achieve the purpose of shortening the duration.

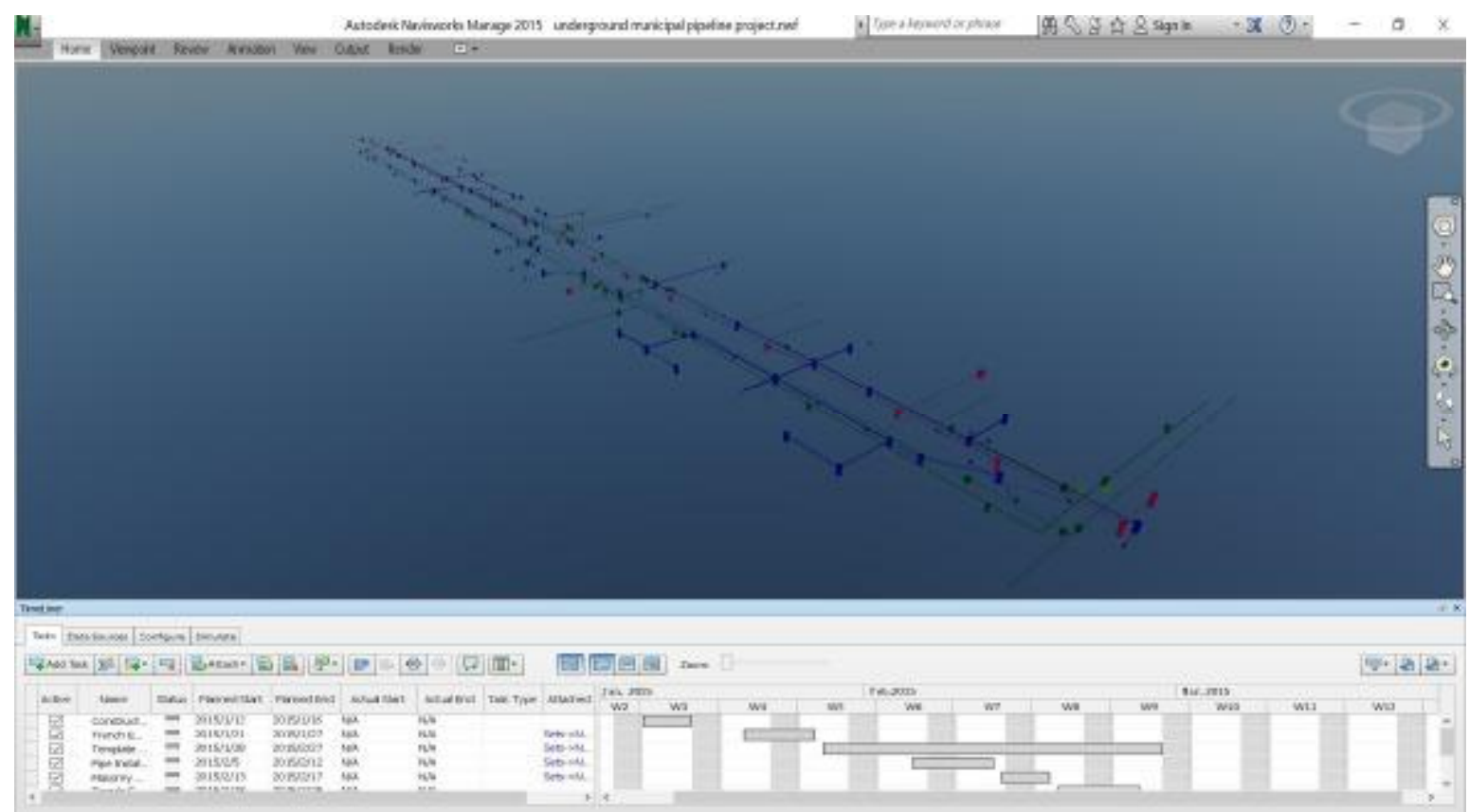

Fig.1 BIM-4D model of the underground pipe network
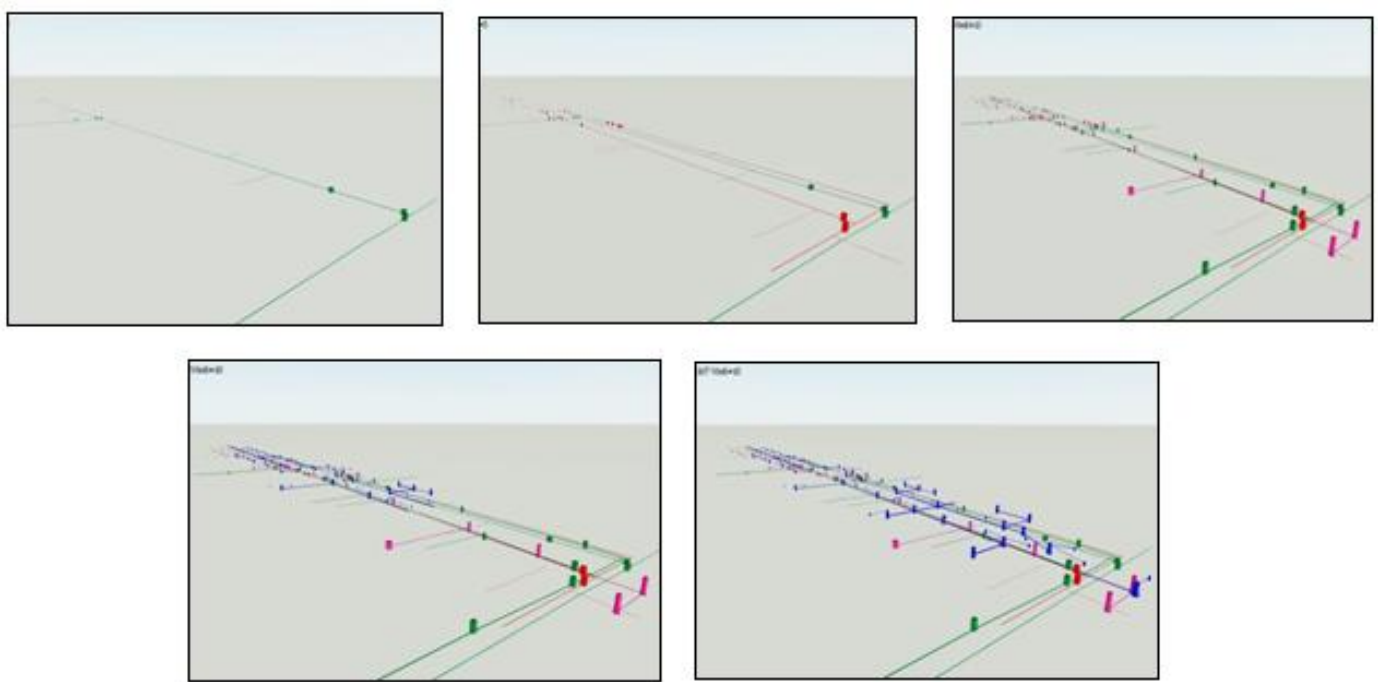

Fig. 2 BIM construction progress simulation tracking

Before the construction, the BIM model can automatically classify the relevant attributes of the schedule and model components and store them in the central document. The data generated by implementation of the project, can be collected directly from the construction site and manually input to the BIM model. In the BIM visualization platform, comparing and analyzing the planned progress and actual progress data will make early warning and timely corrective measures in the model, and correct the optimization project plan, which will help to strengthen the gerentocratic ability to control the progress of the project. In the implementation process of the pipeline network, we can clearly observe the growth process of the project and the comparison between the planned progress and the actual progress by inputting the WBS node task time in real time and comparing the BIM growth model of project schedule and actual progress. As is shown in Figure 3, the green part of the model 
represents the progress which is completed in advance, the red part represents the construction operations which is delayed.

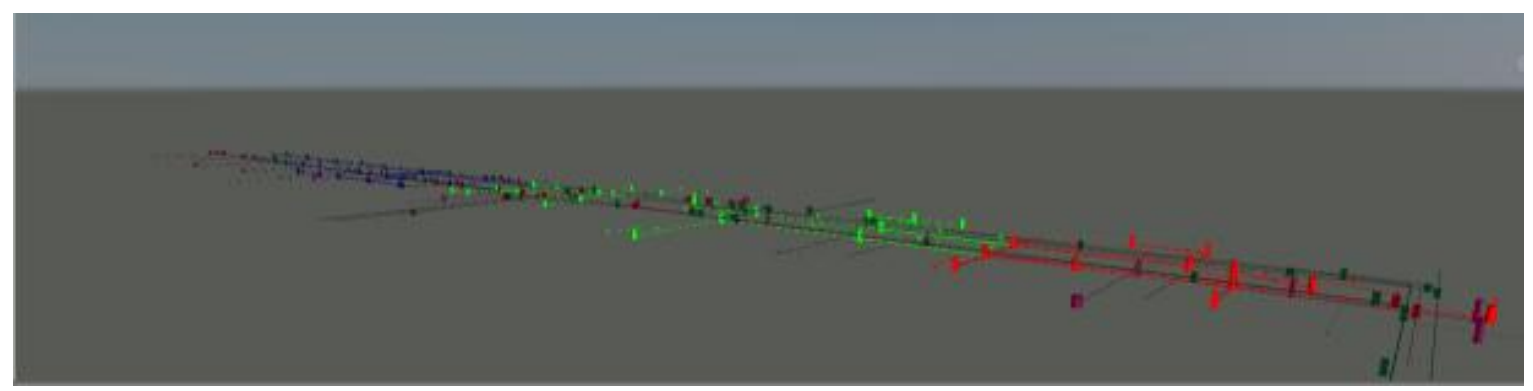

Fig.3 Comparison of the actual construction progress with schedule

In order to avoid the cost estimation and resource allocation seriously deviate from the original plan and other issues caused by schedule deviation, the progress targets need to be adjusted in the project implementation, and take appropriate measures to control the actual progress of the project. Based on visual simulation and analysis function, it helps managers to discover potential problems in the model timely. By continuously adjusting the schedule and optimizing the project plan to ensure the consistency of construction site management and construction schedule management in time and space. In the progress management of the underground pipe network project, to ensure the dynamic updating of project progress data in the BIM-4D model, the project progress file and the BIM model are placed in the same folder. Through the synchronization correlation function, update the adjustment content of progress file into the 4D model in time, and relying on BIM visualization technology, carry the dynamic updated construction schedule for a number of simulation and optimization, so as to control the duration risk more effectively.

\section{Conclusions}

BIM technology improves the input and storage of traditional schedule management information, and displays the project to the staff in a more intuitive way, which solves the problems of information loss and poor delivery in project management. This paper explores the application value of introducing BIM technology to schedule management. By analyzing the application of BIM technology in the construction process of underground municipal pipeline, we can study the promotion of BIM technology to the management of underground municipal pipeline progress. The application of BIM greatly improves the level and work efficiency of progress management, overcomes the difficulties of communication and coordination, project delays and other issues, and also reduce construction costs.

Corresponding author: Miao Qun, Ph.D., professor, municipal engineering.

\section{References}

[1] Eastman, Teicholz, Sacks, Liston, BIM handbook: a guide to building information modeling for owners, managers, architects, engineers, contractors, and fabricators $[\mathrm{M}]$. Wiley, Hoboken, N.J.2011.

[2] G Kerzner, Harold. Project management: a systems approach to planning, scheduling and controlling[M]. New York: John Wiley \& Sons, 2001.

[3] Bosheng Niu, Application Study on Project Schedule Management Base on BIM[D]. Chongqing University, 2012.

[4] Lu Gan, Research on Application of BIM in the Schedule Management of the Construction Project[D]. Dalian University, 2014. 